\title{
A simplified computer model of cardiovascular system with an arm branch ${ }^{1}$
}

\author{
Baoming Chen ${ }^{\mathrm{a}, \mathrm{d}}$, Tianyi Song ${ }^{\mathrm{b}}$, Tao Guo ${ }^{\mathrm{a}}$, Haiyan Xiang ${ }^{\mathrm{c}}$, Yanyong Liu ${ }^{\mathrm{c}}$, Yufei Qin ${ }^{\mathrm{c}}$, \\ Zhengtao $\mathrm{Cao}^{\mathrm{c}}$ and Mengsun $\mathrm{Yu}^{\mathrm{c} \text {,* }}$ \\ ${ }^{a}$ School of Biological and Medical Engineering Beihang University, 37 Xueyuan Rd, Hai Dian District, \\ Beijing 100191, China \\ ${ }^{b}$ General Hospital of Jinan Military Command, 25 Shifan Rd, Tian Qiao District, Jinan 250031, China \\ ${ }^{c}$ Institute of Aviation Medicine Beijing, 28 Fucheng Rd, Hai Dian District, Beijing 100142, China \\ ${ }^{d}$ School of Physics \& Electronic Engineering, Shanxi University, 92 Wucheng Rd, Xiao Dian District, \\ Taiyuan 030006, China
}

\begin{abstract}
Non-invasive pressure simulators that regenerate oscillometric waveforms promise an alternative to expensive clinical trials for validating oscillometric noninvasive blood pressure devices. However, existing simulators only provide oscillometric pressure in cuff and thus have a limited accuracy. It is promising to build a physical simulator that contains a synthetic arm with a built-in brachial artery and an affiliated hydraulic model of cardiovascular system. To guide the construction of this kind of simulator, this paper presents a computer model of cardiovascular system with a relatively simple structure, where the distribution of pressures and flows in aorta root and brachial artery can be simulated, and the produced waves are accordant with the physical data. This model can be used to provide the parameters and structure that will be needed to build the new simulator.
\end{abstract}

Keywords: Computer model, cardiovascular system, brachial artery, non-invasive pressure simulator

\section{Introduction}

Non-invasive automated sphygmomanometers have been widely used to measure blood pressure. Although the readings produced by these instruments have been compared with direct arterial measurements, such comparisons have limited ability to reveal their true accuracy because normal respiratory variations can amount to $10 \mathrm{mmHg}$ or more [1]. Therefore, a hydraulic model of cardiovascular system containing a surrogate arm (Non-invasive pressure simulator) is needed, where a stable standard blood pressure is produced, and can be compared with indirect measurements. Before the model is established, computer simulation should be done to propose appropriate structures and parameters for it.

\footnotetext{
${ }^{1}$ Chen Baoming and Song Tianyi contributed equally to this study and share first authorship.

*Corresponding author: Mengsun Yu, Institute of Aviation Medicine Beijing, 28 Fucheng Rd, Hai Dian District, Beijing 100142, China. Tel.: +86 010 66927047; Fax: +86 010 66927047; E-mail: yms1601@gmail.com.
}

0959-2989/14/\$27.50 @ 2014 - IOS Press and the authors. 
A variety of mathematical models of circulatory system have been developed to guide the constructions of in vitro models. The simple ones, such as [2-5], are mostly based on the Windkessel effect, which helps in damping the fluctuation in blood pressure (pulse pressure) over the cardiac cycle and assists in the maintenance of organ perfusion during diastole when cardiac ejection ceases. These models can approximate the input impedance of the entire systemic tree, but they cannot represent the blood flow distribution nor changes in local or brachial arteries.

In view of that, more complicated computer models [6-9] have been designed to research the distributed properties of the human arterial tree, for example, Koen et al. made a more detailed numerical model [10] which can represent most systemic arteries. Lazzari et al. made a powerful computer model of cardiovascular System [11], which can simulate not only pressure-flow relation of heart and arteries, but heart-lung interaction.

However, for a Non-invasive pressure simulator, it is not necessary to build such a complicated setup according to this theory model, and what the simulator needs to produce is blood pressures just in aortic and brachial arteries [12-14]. This paper proposes a simplified computer model of systemic circulatory system which could simulate the pressures and flows at aortic root and brachial artery. Since a non-invasive automated sphygmomanometer usually doesn't measure the pulse wave transit time, this model can be used to guide the construction of a hydraulic non-invasive pressure simulator.

\section{Methods}

\subsection{Systemic circulation network}

Figure 1 illustrates the computer analogy of the human systemic arterial system, which was an analogous electrical circuit schematic, where charge $\left(C_{1}, C_{2}, C_{3}, C_{4}\right.$ in Figure 1) represented blood volume, current flow, electronic resistance $\left(R_{1}, R_{2}, R_{3}, R_{4}\right.$ in Figure 1) hydraulic resistance, inductance $\left(L_{1}, L_{2}, L_{3}, L_{4}\right.$ in Figure 1) inertance and voltage pressure. This model was aimed at simulating the pressures and flows at the aortic root and in the brachial artery as simply as possible. Hence, only main arteries in the left upper limb were simulated more so than arteries in other parts of the body.

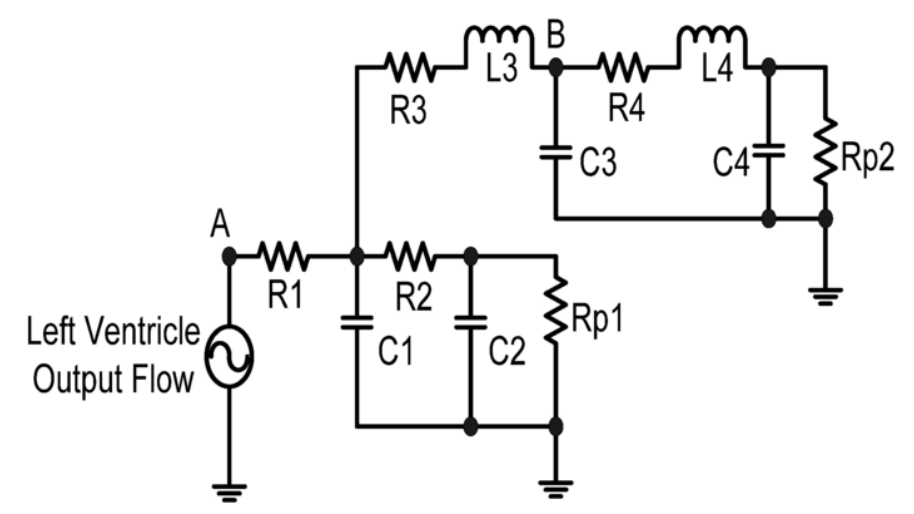

Fig. 1. The mock human circulatory loop. 
Table 1

Values of each element and physical parameters

\begin{tabular}{|c|c|c|c|c|c|c|c|}
\hline \multirow[b]{2}{*}{$\begin{array}{l}\text { Name of Arterial } \\
\text { Segment }\end{array}$} & \multirow[b]{2}{*}{$\begin{array}{l}\text { Length } \\
l(\mathrm{~cm})\end{array}$} & \multirow[b]{2}{*}{$\begin{array}{l}\text { Internal } \\
\text { radius } \\
r(\mathrm{~cm})\end{array}$} & \multirow[b]{2}{*}{$\begin{array}{l}\text { Wall- } \\
\text { thickness } \\
h(\mathrm{~cm})\end{array}$} & \multirow[b]{2}{*}{$\begin{array}{l}\text { Young's } \\
\text { modulus } \\
E(\mathrm{MPa})\end{array}$} & \multicolumn{2}{|c|}{ Values of the elements } & \multirow[b]{2}{*}{$\begin{array}{l}\mathrm{C}\left(\mathrm{mmHg}^{-}\right. \\
\left.{ }^{1} \cdot \mathrm{cm}^{3}\right)\end{array}$} \\
\hline & & & & & $\begin{array}{l}\text { R } \\
\left(\mathrm{mmHg} . \mathrm{s} . \mathrm{cm}^{-}\right. \\
\left.3^{-}\right)\end{array}$ & $\begin{array}{l}\mathrm{L} \\
\left(\mathrm{mmHg} \cdot \mathrm{s}^{2} \cdot \mathrm{cm}^{-}\right.\end{array}$ & \\
\hline \multirow{2}{*}{$\begin{array}{l}\text { Left subclavian and } \\
\text { axillary arteries }\end{array}$} & \multirow{2}{*}{20} & \multirow{2}{*}{0.38} & \multirow{2}{*}{0.065} & \multirow{2}{*}{0.4} & R3 & L3 & $\mathrm{C} 3$ \\
\hline & & & & & 0.3 & 0.04 & 0.01 \\
\hline \multirow{2}{*}{ Brachial artery } & \multirow{2}{*}{23} & \multirow{2}{*}{0.26} & \multirow{2}{*}{0.053} & \multirow{2}{*}{0.4} & $\mathrm{R} 4$ & L4 & $\mathrm{C} 4$ \\
\hline & & & & & 0.5 & 0.08 & 0.01 \\
\hline \multirow{4}{*}{ The other arteries } & \multirow{4}{*}{ None } & \multirow{4}{*}{ None } & \multirow{4}{*}{ None } & \multirow{4}{*}{ None } & R1 & None & $\mathrm{C} 1$ \\
\hline & & & & & 0.02 & None & 1.5 \\
\hline & & & & & $\mathrm{R} 2$ & None & $\mathrm{C} 2$ \\
\hline & & & & & 0.7 & None & 3 \\
\hline \multirow{2}{*}{$\begin{array}{l}\text { Peripheral vessels of } \\
\text { arm }\end{array}$} & \multirow{2}{*}{ None } & \multirow{2}{*}{ None } & \multirow{2}{*}{ None } & \multirow{2}{*}{ None } & $\mathrm{Rp} 2$ & None & None \\
\hline & & & & & 50 & None & None \\
\hline \multirow{2}{*}{$\begin{array}{l}\text { The other peripheral } \\
\text { vessels }\end{array}$} & \multirow{2}{*}{ None } & \multirow{2}{*}{ None } & \multirow{2}{*}{ None } & \multirow{2}{*}{ None } & Rp1 & None & None \\
\hline & & & & & 0.5 & None & None \\
\hline
\end{tabular}

The elements numbered 4 in Figure 1 represented the brachial artery in the arm. The left subclavian and axillary arteries were approximately equal in diameter. The left subclavian and axillary arteries are approximately equal in diameter and Young's modulus, then according to Eq. (3), they can be treated as one blood vessel simulated by elements numbered 3 .

The values of these elements, such as $R, L$ and $C$, were calculated by

$$
\begin{aligned}
& R=81 \mu l / 8 \pi r^{4} \\
& L=9 \rho l / 4 \pi r^{2} \\
& C=3 \pi r^{3} l / 2 E h
\end{aligned}
$$

Respectively [15], where was ordinary coefficient of blood viscosity $(0.004 \mathrm{~Pa} \cdot \mathrm{s}), l$ was the vessel length, $r$ was the vessel inner radius was blood mass density $\left(1000 \mathrm{~kg} / \mathrm{m}^{3}\right), E$ denotes the Young's modulus and $h$ was thickness of the vessel wall. The other arterial vessels of the arm, including the radial artery, the ulnar artery and peripheral resistance vessels were approximately simulated by a resistance $R p_{2}$ in Figure 1 which was evaluated by dividing the mean pressure at the entrance of the left subclavian artery with the mean flow. The other elements constituted a windkessel model simulating the impedance of the left arteries in human as a whole, whose values were estimated according to [16]. Table 1 lists the quantities and physical parameters involved in the model.

\subsection{Left ventricle model}

The left ventricle was simulated as a flow source, which produced a flow pattern similar to the natural heart, independent of load. The flow data were synthesized by sinusoidal Fourier series, and the Fourier coefficients were drawn from a man with a stroke volume of $88 \mathrm{ml}$ and a heart rate of 1.25 $\mathrm{Hz}$ [17]. As is shown in Figure 2, the left ventricle model was composed of ten sine flow sources, each of which had a frequency from zero to tenfold the heart rate. Coupled with a unilateral diode, the 


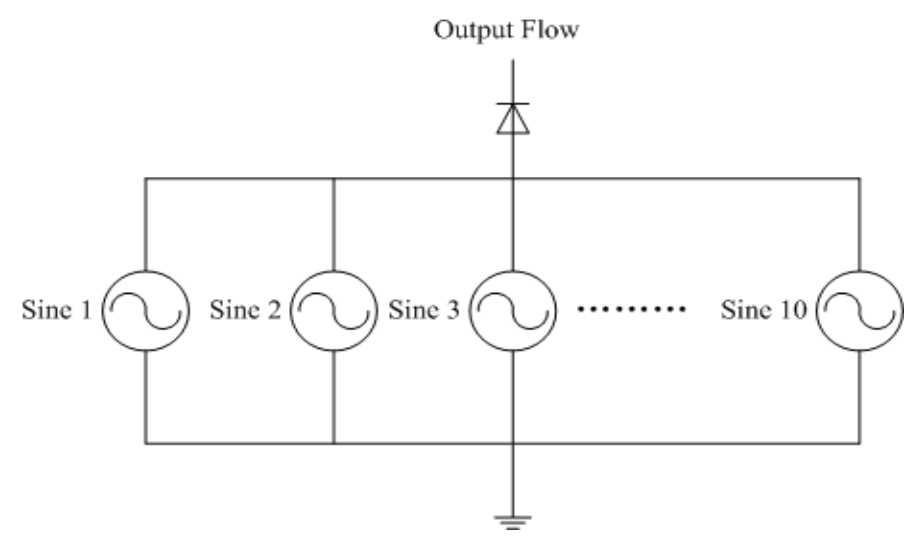

Fig. 2. Model of left ventricle.

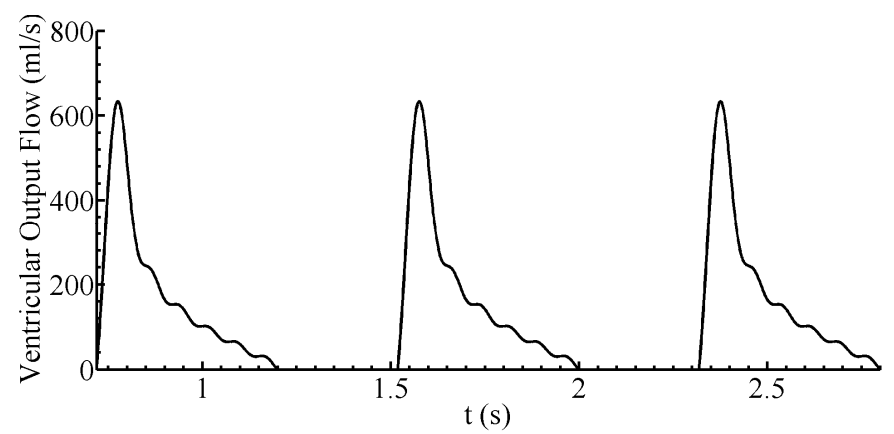

Fig. 3. Curve of ventricular output flow.

blood was ejected into the arterial network only in systole. The peak of the left ventricular output flow was about $630 \mathrm{ml} / \mathrm{s}$ and the mock flow was more fluctuant in diastole than physical because it contained limited harmonics (Figure 3).

\subsection{Matlab simulation method}

Using the simpower systems module in Matlab, the computer model could be constructed in a visual

Table 2

Values Conversion from hemodynamic to electrical quantities

\begin{tabular}{lll}
\hline Physical quantity & Hemodynamic & Electrical \\
\hline Pressure & $1 \mathrm{mmHg}$ & $b \mathrm{~V}^{\mathrm{a}}$ \\
Volume & $1 \mathrm{~cm}^{3}$ & $0.752 b 10^{-6} \mathrm{C}$ \\
Time & $1 \mathrm{~s}$ & $10^{-3} \mathrm{~s}$ \\
Flow & $1 \mathrm{ml} \cdot \mathrm{s}^{-1}$ & $0.752 b 10^{-3} \mathrm{~A}$ \\
Frequency & $1 \mathrm{~Hz}$ & $10^{3} \mathrm{~Hz}$ \\
Resistance & $1 \mathrm{mmHg} \cdot \mathrm{s}^{-\mathrm{cm}^{-3}}$ & $10^{3} / 0.752$ \\
Inertance & $1 \mathrm{mmHg} \cdot \mathrm{s}^{2} \cdot \mathrm{cm}^{-3}$ & $1010 / 760 \mathrm{H}$ \\
Elasticity & $1 \mathrm{mmHg} \cdot \cdot \mathrm{cm}^{3}$ & $0.752 \cdot 10^{-6} \mathrm{~F}$ \\
\hline${ }^{\mathrm{a}} b=0.01$ & &
\end{tabular}


way like building a circuit as is shown in Figure 1. However, the units of the parameters in Table 1 for the elements in Figure 1 were still in the field of hemodynamics. They had to be converted to electrical parameters (Table 2).

\section{Results and discussion}

Figure 4 shows the amplitude and phase characteristics of the input impedance at point $\mathrm{A}$ in the model, corresponding to the input impedance of the systemic circulation in human. Under normal physiological conditions, the amplitude of the impedance of the systemic circulation system decreases rapidly when the frequency is slightly above zero. Then, as the frequency increases, the impedance characteristic curve begins to fluctuate around the characteristic impedance. In high frequency section, the amplitude tends to be stable equaling to the characteristic impedance. Compared to the measured physical data [18], the model has simulated the main features of the human input impedance. However, there was no variation in middle frequency band as the human's, due to the defects of the applied windkessel model.

As is shown in Figure 5, the simulated pressure waves in the aortic root and brachial artery were close to the physical data [18]. The systolic and diastolic pressure differences between the aorta and the brachial artery were both less than $3 \mathrm{mmgH}$, lying in the normal range, and their mean pressures were close to equal. When the heart rate was set to a fixed value of $75 \mathrm{~Hz}$, the simulation results for different stroke volume are shown in Table 3. As was mentioned in [18], the systolic blood pressure increased more significantly than diastolic blood pressure when stroke volume rose, resulting in an augmented pulse pressure. When stroke volume was set to a fixed value of $65 \mathrm{ml}$, the simulation results for different heart rates are shown in Table 4. As the heart beats speeded up, due to the shortened diastolic period, the blood flow to the peripheral vessels reduced and more blood remained in the aorta at the end of diastole. Therefore the diastolic blood pressure rose, while the systolic one slightly lowered, resulting in a decreased pulse pressure. These findings were consistent with the projected results in literature [18].

The waveform in Figure 6 represents the simulated flow in the brachial artery, the contour of which was accordant with the data measured in man. The mean flow in this segment was about $3 \%$ of the cardiac output, as reported in [18].

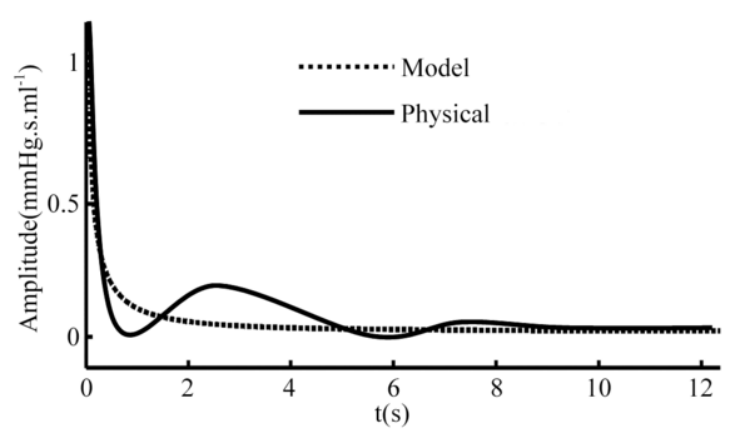

(a)

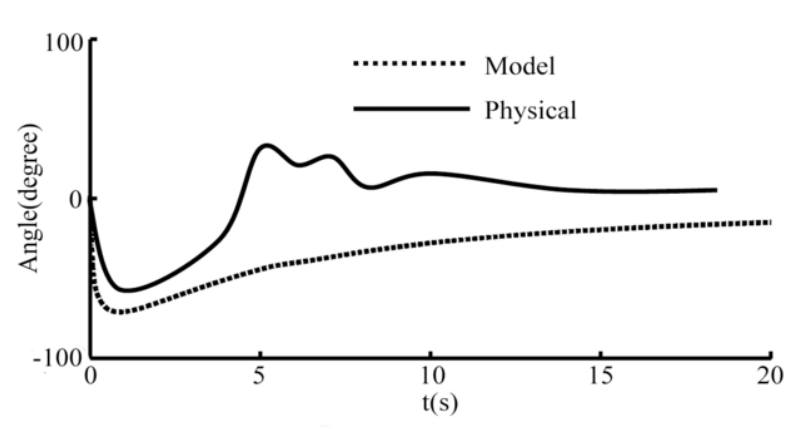

(b)

Fig. 4. Input impedance of the model compared with human. (a): modulus and (b): phase. 


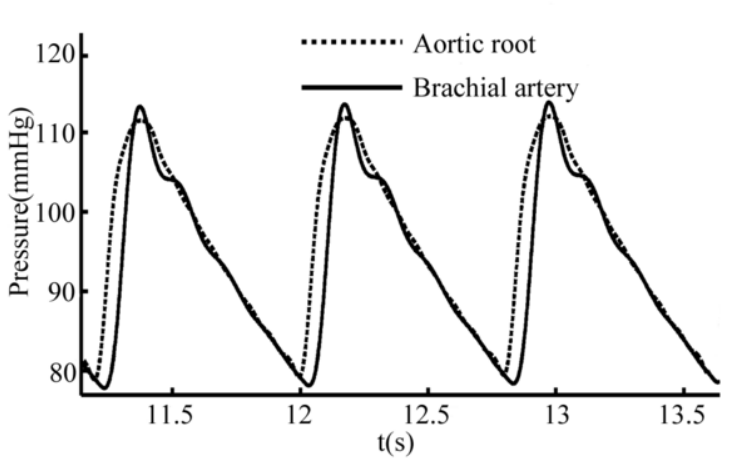

Fig. 5. Simulated pressures in aortic root and brachial artery.

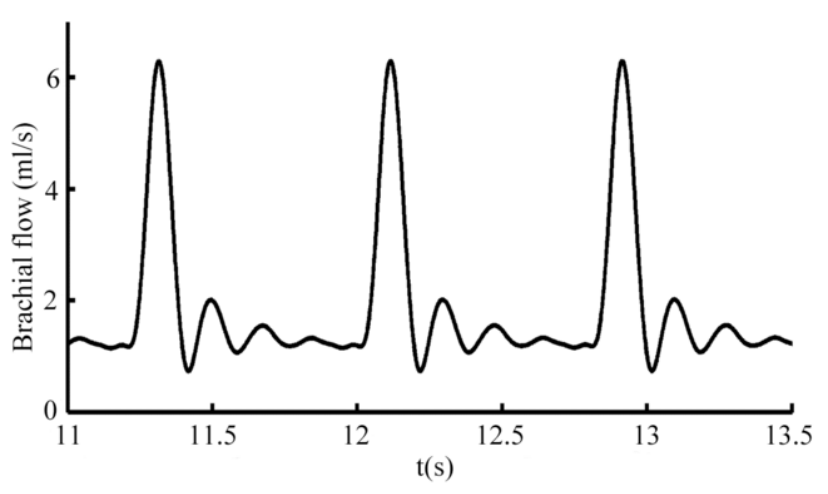

Fig. 6. Simulated brachial flow.

Table 3

Simulation results corresponding to different stroke volume (SV)

\begin{tabular}{lllll}
\hline $\begin{array}{l}\mathrm{HR} \\
(\mathrm{Hz})\end{array}$ & $\begin{array}{l}\mathrm{SV} \\
(\mathrm{ml})\end{array}$ & $\begin{array}{l}\text { Aortic BP } \\
(\mathrm{DBP}-\mathrm{SBP}, \mathrm{mmHg})\end{array}$ & $\begin{array}{l}\text { Brachial BP } \\
(\mathrm{DBP}-\mathrm{SBP}, \mathrm{mmHg})\end{array}$ & $\begin{array}{l}\text { Aortic Pulse BP } \\
(\mathrm{mmHg})\end{array}$ \\
\hline & 50 & $57-86$ & $56-87$ & 29 \\
75 & 60 & $68-102$ & $67-105$ & 34 \\
& 65 & $74-111$ & $73-113$ & 37 \\
& 70 & $80-120$ & $79-122$ & 40 \\
& 80 & $91-136$ & $90-139$ & 45 \\
\hline
\end{tabular}

Table 4

Simulation results corresponding to different heart rate

\begin{tabular}{cllll}
\hline $\begin{array}{l}\text { SV } \\
(\mathrm{ml})\end{array}$ & $\begin{array}{l}\mathrm{HR} \\
(\mathrm{Hz})\end{array}$ & $\begin{array}{l}\text { Aortic BP } \\
(\mathrm{DBP}-\mathrm{SBP}, \mathrm{mmHg})\end{array}$ & $\begin{array}{l}\text { Brachial BP } \\
(\mathrm{DBP}-\mathrm{SBP}, \mathrm{mmHg})\end{array}$ & $\begin{array}{l}\text { Aortic Pulse BP } \\
(\mathrm{mmHg})\end{array}$ \\
\hline & 60 & $70-115$ & $70-114$ & 45 \\
& 70 & $73-112$ & $72-114$ & 39 \\
65 & 75 & $74-111$ & $73-113$ & 37 \\
& 80 & $75-110$ & $74-113$ & 35 \\
& 90 & $76-108$ & $75-112$ & 32 \\
\hline
\end{tabular}

\section{Conclusion}

This paper has explained a computer mock system of human systemic circulation with a considerably simple structure. It could correctly simulate the pressure and flow waves in the aorta and brachial artery. The model applies the simple 3-element windkessel model to represent the arterial system and the derived impedance curve in the middle frequency band does not comply with the physiological reality. To improve this situation, in the follow-up attempt a more sophisticated model using dual elastic chambers will be applied. Although this model couldn't simulate the phenomenon of pulse wave transmission, it could be used to guide the construction of a hydraulic non-invasive pressure simulator, because a non-invasive automated sphygmomanometer usually doesn't measure the pulse wave transit time and the related explanation has been added in the part of introduction. 


\section{Acknowledgement}

This work is partially supported by Key Technologies Research and Development Program of China \#2011BAI02B08 to Tao Guo, \#2013BAI03B02 to Haiyan Xiang and National Natural Science Foundation of China \#81271737 to Haiyan Xiang.

\section{References}

[1] E. Balestrieri and S. Rapuano, Instruments and methods for calibration of oscillometric blood pressure measurement devices, IEEE Transactions on Instrumentation and Measurement 9 (2010), 2391-2404.

[2] N. Westerhof, J.W. Lankhaar and B.E. Westerhof, The arterial Windkessel, Med. Biol. Eng. Comput. 2 (2009), 131141.

[3] W.M. Swanson and R.E. Clark, A simple cardiovascular system simulator: Design and performance, J. Bioeng. 2 (1977), 135-145.

[4] G. Avanzolini, P. Barbini, A. Cappello et al., CADCS simulation of the closed-loop cardiovascular system, Int. J. Biomed. Comput. 1 (1988), 39-49.

[5] R. Zannoli, I. Corazza and A. Branzi, Mechanical simulator of the cardiovascular system, Phys. Med. 2 (2009), 94-100.

[6] B.M. Hanson, M.C. Levesley, K. Watterson et al., Hardware-in-the-loop-simulation of the cardiovascular system, with assist device testing application, Med. Eng. Phys. 3 (2007), 367-374.

[7] C.L. Felipini, A.J. de Andrade, J.C. Lucchi et al., An electro-fluid-dynamic simulator for the cardiovascular system, Artif. Organs. 4 (2008), 349-354.

[8] P. Ruiz, M.A. Rezaienia, A. Rahideh et al., In vitro cardiovascular system emulator (bioreactor) for the simulation of normal and diseased conditions with and without mechanical circulatory support, Artif. Organs. 6 (2013), 549-560.

[9] A. Quarteroni and L. Formaggia, Mathematical modelling and numerical simulation of the cardiovascular system, Handbook of Numerical Analysis 12 (2004), 3-127.

[10] K.S. Matthys, J. Alastruey, J. Peiro et al., Pulse wave propagation in a model human arterial network: Assessment of 1D numerical simulations against in vitro measurements, J. Biomech. 15 (2007), 3476-3486.

[11] C. De Lazzari, I. Genuini, D. Pisanelli et al., Simulation for enhancing e-Learning environments: A software for teaching heart-lung interaction to medicine students, Budapest, 2013, 197-202.

[12] P.D. Davis, J.L. Dennis and R. Railton, Evaluation of the A \& D UA-767 and welch allyn spot vital signs noninvasive blood pressure monitors using a blood pressure simulator, J. Hum. Hypertens. 3 (2005), 197-203.

[13] W. Riedel, S. Mieke, R. Seemann et al., A simulator for oscillometric blood-pressure signals to test automated noninvasive sphygmomanometers, Rev. Sci. Instrum. 82 (2011), 24303. doi: 10.1063/1.3549803

[14] G.S. Chan, P.N. Ainslie, C.K. Willie et al., Contribution of arterial windkessel in low-frequency cerebral hemodynamics during transient changes in blood pressure, J. Appl. Physiol. 4 (1985), 917-925.

[15] V.C. Rideout and D.E. Dick, Difference-differential equations for fluid flow in distensible tubes, IEEE Transactions on Biomedical Engineering 3 (1967), 171-177.

[16] H. Huan, Y. Ming, Z. Wangfu et al., In vitro identification of four-element windkessel models based on iterated unscented kalman filter, Transactions on Biomedical Engineering 9 (2011), 2672-2680.

[17] V. Taviani, S.S. Hickson, C.J. Hardy et al., Estimation of aortic pulse pressure using fourier velocity encoded M-mode MR, J. Magn. Reson. Imaging 1 (2014), 85-93.

[18] N. Westerhof, N. Stergiopulos and M.I.M. Noble, Snapshots of Hemodynamics-An Aid for Clinical Research and Graduate Education, Springer, US, 2005. 